ARTICLE

\title{
Directed transforming of coke to active intermediates in methanol-to-olefins catalyst to boost light olefins selectivity
}

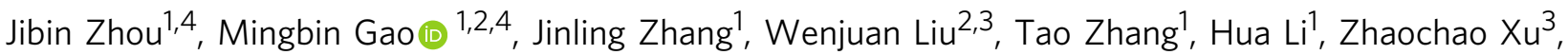
Mao Ye(iD ${ }^{1 凶} \&$ Zhongmin Liu (iD) ${ }^{1,2}$

Methanol-to-olefins (MTO), the most important catalytic process producing ethylene and propylene from non-oil feedstocks (coal, natural gas, biomass, $\mathrm{CO}_{2}$, etc.), is hindered by rapid catalyst deactivation due to coke deposition. Common practice to recover catalyst activity, i.e. removing coke via air combustion or steam gasification, unavoidably eliminates the active hydrocarbon pool species (HCPs) favoring light olefins formation. Density functional theory calculations and structured illumination microscopy reveal that naphthalenic cations, active HCPs enhancing ethylene production, are highly stable within SAPO-34 zeolites at high temperature. Here, we demonstrate a strategy of directly transforming coke to naphthalenic species in SAPO-34 zeolites via steam cracking. Fluidized bed reactor-regenerator pilot experiments show that an unexpectedly high light olefins selectivity of $85 \%$ is achieved in MTO reaction with $88 \%$ valuable $\mathrm{CO}$ and $\mathrm{H}_{2}$ and negligible $\mathrm{CO}_{2}$ as byproducts from regeneration under industrial-alike continuous operations. This strategy significantly boosts the economics and sustainability of MTO process.

\footnotetext{
${ }^{1}$ National Engineering Laboratory for Methanol to Olefins, Dalian National Laboratory for Clean Energy, Dalian Institute of Chemical Physics, Chinese Academy of Sciences, Dalian, China. ${ }^{2}$ University of Chinese Academy of Sciences, Beijing, China. ${ }^{3}$ Key Laboratory of Separation Science for Analytical Chemistry, Dalian Institute of Chemical Physics, Chinese Academy of Sciences, Dalian, China. ${ }^{4}$ These authors contributed equally: Jibin Zhou, Mingbin Gao.

凶email: maoye@dicp.ac.cn; liuzm@dicp.ac.cn
} 
S ince its first commercialization in $2010^{1}$, methanol-toolefins (MTO) over zeolitic catalyst has become the most important process producing light olefins (ethylene and propylene) from non-oil feedstocks such as coal, natural gas, biomass, and $\mathrm{CO}_{2}{ }^{1-5}$. Despite essential progress achieved in both fundamental and applied research in the past decades, concurrently pursuing long catalyst lifetime and high light olefins selectivity in MTO remains an open challenge so far ${ }^{2,6}$. As an archetypical co-catalysis reaction, catalytic performance in MTO is manipulated by the organic intermediates confined in zeolite channels or cavities through the sophisticated hydrocarbon pool mechanism $^{3,7-9}$. These hydrocarbon pool species (HCPs), typically including the methyled-benzene carbocations ${ }^{10,11}$ and cyclopentadienyl species ${ }^{12,13}$, are decisive for light olefins selectivity, owning to the altering of acidity ${ }^{14}$, reaction paths ${ }^{15}$, kinetics $^{8,9}$, molecular transport ${ }^{16}$, and among others. However, the HCPs are also coke precursors that can readily evolve to polycyclic aromatic hydrocarbons (PAHs), the typical coke species, through cyclization ${ }^{17}$ and cross-linked mechanism ${ }^{18,19}$, accelerating catalyst deactivation ${ }^{20}$. Therefore, such dual-role of HCPs impedes achieving superior light olefins selectivity while maintaining long catalyst lifetime in MTO over zeolitic catalyst. In catalytic processes accompanying with catalyst deactivation by coke deposition, e.g., MTO and fluid catalytic cracking (FCC), air combustion or steam gasification ${ }^{21,22}$ has been used as common practices to eliminate coke for catalytic activity recovering. This unavoidably lowers light olefins selectivity because the active HCPs favoring light olefins formation in the catalyst have been meantime eliminated. However, the reinstitution of HCPs in nano-cavity of zeolite catalyst is of equal importance in recovering acidity and prompting light olefins selectivity. In this connection, a logical question follows: can the coke inevitably causing catalyst deactivation be selectively transformed to active HCPs?

Some methods have been proposed to modulate the product selectivity via tailoring the HCPs confined in zeolites for MTO reactions. By use of mimics of the HCPs as organic structuredirecting agents (OSDAs) to synthesize CHA and RTH-related zeolites, it is possible to maximize the host-guest interaction between framework and polymethyl aromatic intermediates to promote the propylene/ethylene ratio ${ }^{8,11}$. However, precise design and synthesis of targeted zeolites with specific OSDAs are extremely challenging ${ }^{23}$, especially the HCPs slightly different in structures may significantly change the product selectivity ${ }^{8}$. Cofeeding of methanol with organic intermediates, e.g., alkenes ${ }^{24}$, aromatics $^{25}$ or formaldehyde ${ }^{26}$, has also been applied to adjust ethylene/propylene ratio via altering the HCPs dominating either olefinic or aromatic cycle ${ }^{2,6}$ according to dual-cycle mechanism. Unfortunately, co-feeding of aromatics suffers significant diffusion limitation owning to the steric hindrance of nanopore of zeolite framework ${ }^{1,27}$. Pre-synthesis specific active HCPs inside vacant cavity of SAPO-34 zeolite by methanol ${ }^{28}$ or n-butene ${ }^{15}$ at high temperatures can also favor ethylene formation. In the aforementioned methods, nevertheless, the light olefins selectivity can be modulated to certain extent by tuning HCPs with assistance of external reactants. Formation of coke and thus catalyst deactivation, as a result of evolution of HCPs within zeolites, are still major concern in these methods.

Here, we demonstrate a regeneration strategy to directionally transform coke to active HCPs within nano-confined spaces of industrially important SAPO-34 zeolites. Theoretically the steric stability and functionality are two metrics for screening scaffold of HCPs confined in nano-space ${ }^{17}$. We first conduct density functional theory (DFT) calculations and find that naphthalenic species, which favor ethylene formation are spatially-stable within CHA cavity at high temperature. Thus coke within the deactivated catalyst, i.e., mainly PAHs, can in principle be transformed to naphthalenic species via thermal cracking at high temperature. In doing so, we sweep coked SAPO-34 catalyst with nitrogen under high temperature and obtain naphthalenic species-rich SAPO-34 zeolite (Fig. 1a), which exhibits high light olefins selectivity but poor methanol conversion. We further study two mediums commonly used for ring-opening of PAHs, i.e., hydrogen and steam, via DFT calculations. Comparison of energy barriers shows that steam, despite being the main byproduct in MTO, is more effective in cracking coke to naphthalenic species in SAPO-34 zeolites. Laboratory experimental results demonstrate that directionally transforming coke confined in SAPO-34 zeolites to naphthalenic species by steam cracking, not only restores the catalytic activity but also promotes light olefins selectivity in MTO reaction. In addition, steam cracking of coke releases only a small amount of byproducts in the form of flue gas, which is dominantly composed of valuable syngas $\left(\mathrm{H}_{2}\right.$ and $\mathrm{CO}$ ) with negligible greenhouse gas $\mathrm{CO}_{2}$ (Fig. 1b). By verifying it in a fluidized bed reactor-regenerator pilot plant, we show this strategy can significantly boost the economics and sustainability of industrial MTO process.

\section{Results}

Stability and functionality of intermediates confined in CHA cavity. It is well recognized that the organic intermediates confined in nano-cavity play the crucial role in determining the product selectivity for MTO reaction ${ }^{7,9-11}$. As reaction proceeds, the transformation of monocyclic aromatic to PAHs is inevi-

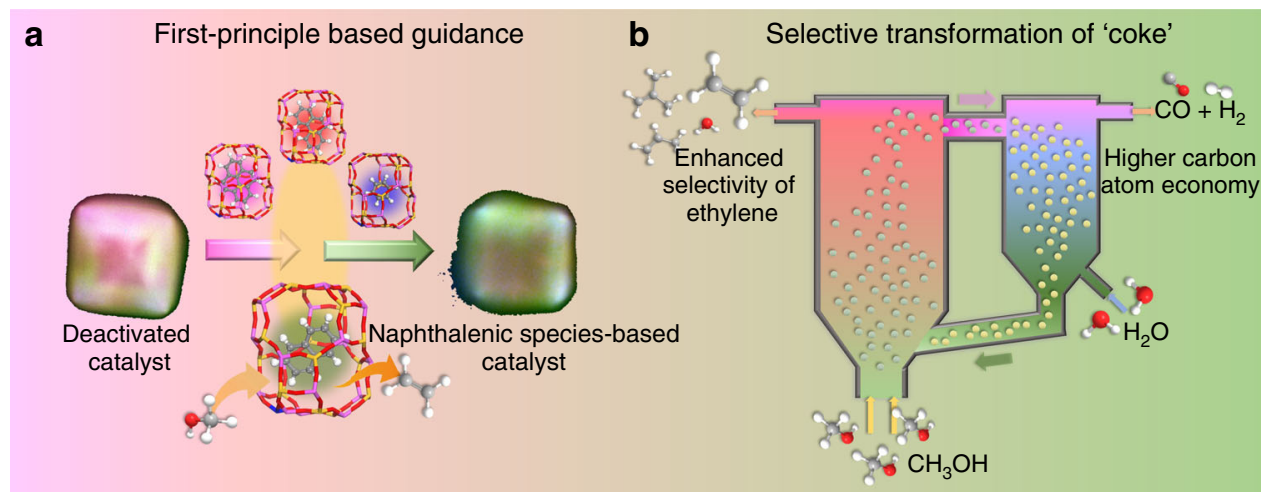

Fig. 1 Schematic illustrations of selective transformation of coke into specific intermediates. a First-principle-based simulations provide the criteria of stability and functionality of organic intermediates confined in nano-cavity. b Selective transformation of coke into specific naphthalenic species-rich catalyst, and improvement of MTO performance and atom economy implemented in the circulating fluidized bed reactor-regenerator configuration. 
a

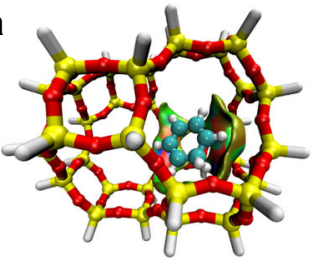

$\Delta G_{\text {ads }}(953 \mathrm{~K})=-53.09 \mathrm{~kJ} \mathrm{~mol}^{-1} \Delta G_{\mathrm{ads}}(953 \mathrm{~K})=-68.67 \mathrm{~kJ} \mathrm{~mol}^{-1}$

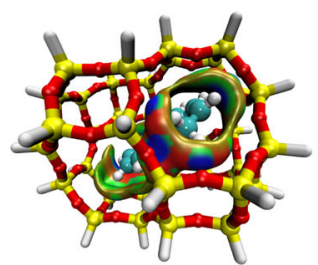

$\Delta G_{\mathrm{ads}}(953 \mathrm{~K})=-20.62 \mathrm{~kJ} \mathrm{~mol}^{-1}$
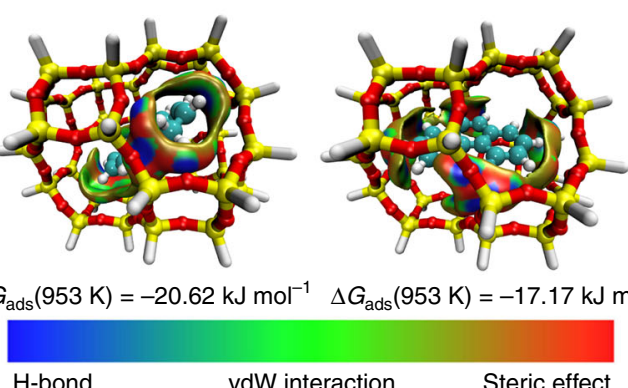

$\Delta G_{\text {ads }}(953 \mathrm{~K})=-17.17 \mathrm{~kJ} \mathrm{~mol}^{-1}$

vdW interaction

H-bond

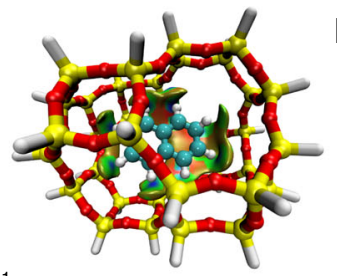

b

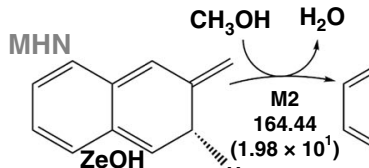

"

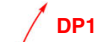

85.05

$\left(1.08 \times 10^{7}\right)$

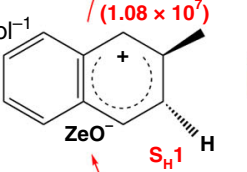

$\mathrm{S}_{\mathrm{H}} 1$

$\left(4.20 \times 10^{9}\right)$<smiles>Cc1cccc2ccccc12</smiles>

$\underbrace{+\ldots}_{\mathrm{ZeO}^{-}}$

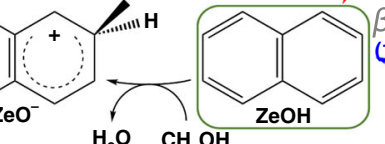

$\mathrm{H}_{2} \mathrm{O} \mathrm{CH}_{3} \mathrm{OH} \mathrm{ZeOH} \mathrm{C}_{3} \mathrm{H}_{6}$

Steric effect

$\left.2.45 \times 10^{9}\right)$
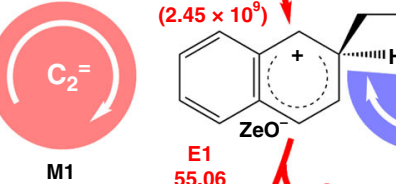

E1 E1 145.60
$\left(4.56 \times 10^{2}\right)$

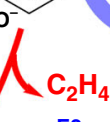

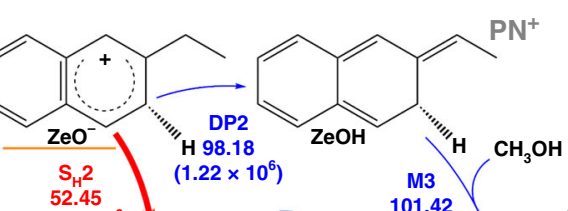
101.42
$\left(7.08 \times 10^{5}\right)$ $\mathrm{H}_{2} \mathrm{O}$

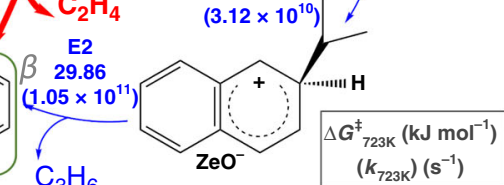

Fig. 2 Guidance from density functional theory to screen the stable and functional intermediates. a Isosurface plots of the reduced density gradient and Gibbs free energy of adsorption at $953 \mathrm{~K}$ for the benzenic, naphthalenic, phenanthrenic, and pyrenic carbenium ions confined in neutral pure silica model of $\mathrm{CHA}$ cavity. The isosurfaces of the reduced density gradient are colored according to the values of the quantity sign $\left(\lambda_{2}\right) \rho$ with the indicated RGB scale.

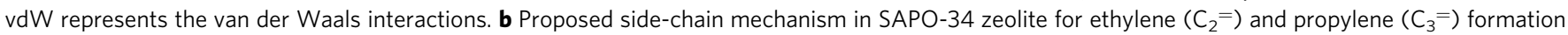
starting from sterically stabilized naphthalene. Gibbs free energy in $\mathrm{kJ} \mathrm{mol}^{-1}$ and intrinsic rate coefficient in $1 \mathrm{~s}^{-1}$ (in parentheses) at $723 \mathrm{~K}$

table ${ }^{1}$. Therefore, it is hard to solely identify the functionality of specific intermediates confined in zeolites during reaction by experiments. The steric stabilities of benzenic $\left(\mathrm{B}_{\mathrm{n}}^{+}\right)$, naphthalenic $\left(\mathrm{N}_{\mathrm{n}}^{+}\right)$, phenanthrenic $\left(\mathrm{PH}_{\mathrm{n}}{ }^{+}\right)$, and pyrenic $\left(\mathrm{PYR}_{\mathrm{n}}{ }^{+}\right)$carbocations with $n$ methyl substituent confined within negative SAPO-34 zeolite model (Supplementary Table 6) and neutral pure silica model of CHA cavity (Supplementary Table 7) at a high temperature $(953 \mathrm{~K})$, in terms of the adsorption Gibbs free energy $\left(\Delta G_{\text {ads }}\right)$, are calculated by DFT. According to the calculated results, naphthalenic carbocation is the preferentially stable carbenium ions within negative SAPO-34 zeolite model and pure silica model of $\mathrm{CHA}$ at $953 \mathrm{~K}$. In addition, this implies the dominated stabilization effect is imposed by CHA confinement. Similarly, the calculated results of neutral carbonaceous species within neutral SAPO-34 model containing Brønsted acid site, also verify that the preferentially stable carbonaceous species within CHA cavity is naphthalene species (Supplementary Table 8). In Fig. 2a, in the pure silica model of CHA, the isosurface plots of reduced density gradient for phenanthrenic and pyrenic carbocations exhibit enriched van der Waals (vdW) stabilization interaction at the border of molecules from the zeolite framework instead of enveloping the whole molecules like benzenic and naphthalenic carbocations. Moreover, owning to the small spatial occupancy of benzenic carbocations, the interaction imposed by zeolite framework is relatively weaker than that of naphthalenic carbocations. These confirm again that the chemical environment of $\mathrm{CHA}$ cavity leads to the more preferential stabilization of naphthalenic carbocations from the perspective of molecular level.

In Fig. 2b, the full catalytic cycle with Gibbs free energy and intrinsic rate coefficient at $723 \mathrm{~K}$ for ethylene and propylene formation starting from naphthalene is presented. To verify the calculations, the calculated results were compared with the previous work. The calculated Gibbs free energies of $\mathrm{M} 1$ and $\mathrm{S}_{\mathrm{H}} 1$ are 144.07 and $49.26 \mathrm{~kJ} \mathrm{~mol}^{-1}$ at $670 \mathrm{~K}$, respectively, which are close to the calculated results by Hemelsoet et al. ${ }^{29,30}$ (136.4 and $36.4 \mathrm{~kJ} \mathrm{~mol}^{-1}$, respectively). The slightly difference in free energies may be caused by the different calculated approaches. The Gibbs free energy of M2 of 2-methylene-3-hydronaphthalene
(MHN) is $161.68 \mathrm{~kJ} \mathrm{~mol}^{-1}$ at $670 \mathrm{~K}$, which is lower than exocyclic methylation of the 1,1-methy-2-methylene-hydronaphthalene at $670 \mathrm{~K}\left(175.7 \mathrm{~kJ} \mathrm{~mol}^{-1}\right)^{30}$. Owing to the strong steric hindrance imposed by two methyl of 1,1-dimethy-2-methylene-hydronaphthalene during exocyclic methylation, the Gibbs free energy of M2 is lower than that of exocyclic methylation of 1,1-methy-2methylene-hydronaphthalene. At $723 \mathrm{~K}$, naphthalene undergoes methylation $\mathrm{M} 1$ at the position of the $\beta$-carbon atom (Fig. 2b), which shows high free energy barriers $\left(145.60 \mathrm{~kJ} \mathrm{~mol}^{-1}\right)$. However, at $723 \mathrm{~K}$, the intrinsic rate coefficient can be effectively improved to $4.56 \times 10^{2} \mathrm{~s}^{-1}$ compared to $0.16 \times 10^{2} \mathrm{~s}^{-1}$ of $623 \mathrm{~K}$ (Supplementary Table 10), which means the reaction is more feasible through elevating temperature and naphthalene species can be considered as active HCPs at $723 \mathrm{~K}$. Subsequently, 2methyl-naphthalenic cation $\left(\mathrm{MN}^{+}\right)$gets hydride-shifted $\left(\mathrm{S}_{\mathrm{H}} 1\right)$ and deprotonated (DP1), with the formation of (MHN) with moderate free energy barriers of 49.21 and $85.05 \mathrm{~kJ} \mathrm{~mol}^{-1}$, respectively. In the following step, the exocyclic double bond of MHN gets methylated (M2) and the exocyclic methylation M2 is strongly exothermic $\left(\Delta H_{\mathrm{r}}=-81.72 \mathrm{~kJ} \mathrm{~mol}^{-1}\right.$, Supplementary Table 9) and manifests a higher free energy barriers $(164.44 \mathrm{~kJ}$ $\mathrm{mol}^{-1}$ ) than M1. Thus, this is one of the slowest steps in the full catalytic cycle. To realize the catalytic cycle starting from naphthalenic cations, elevating reaction temperature is necessary. For instance, the intrinsic rate coefficient can be effectively improved from $0.07 \times 10^{1} \mathrm{~s}^{-1}$ at $623 \mathrm{~K}$ to $1.98 \times 10^{1} \mathrm{~s}^{-1}$ at $723 \mathrm{~K}$ for M2 step. In this work, the Gibbs free energies of formation of ethylene and propylene from naphthalene derivative were calculated. Then the exocyclic hydrogen migrates relatively fast $\left(2.45 \times 10^{9} \mathrm{~s}^{-1}\right)$ toward the ring carbon whereto the ethyl sidechain is connected, which can be conducive to the broken of exocyclic $\mathrm{C}-\mathrm{C}$ bonds for the ethylene split-off. The elimination E1 therewith promptly occurs through a concerted mechanism with rapid rate $\left(1.58 \times 10^{9} \mathrm{~s}^{-1}\right)$ (Supplementary Table 10), in which the $\mathrm{C}-\mathrm{C}$ bond is broken and the ethyl side-chain is deprotonated with ethylene formation simultaneously with the assistance of water ${ }^{31,32}$, and closes the catalytic cycle. The carbonaceous intermediates where the ethylene and propylene formation cycles bifurcate are indicated with orange line in 
Fig. 2b. The fashion of propylene formation is similar to that of ethylene, but the ethyl side-chain in the product of methylation M2 undergoes a second exocyclic deprotonation DP2 and methylation M3, with intrinsic rate coefficients three orders of magnitude lower compared to $\mathrm{S}_{\mathrm{H}} 2$ in Fig. 2b. This bifurcation (orange line in Fig. 2b) determines that the formation of ethylene is more preferential in catalytic cycle starting from naphthalenic cations. After rapid hydride-shift of hydro 2-propyl-3hydronaphthalene $\left(\mathrm{PN}^{+}\right)$, propylene is easily split off by elimination E2 in a concerted step. The role of naphthalenic cations in MTO reaction hereto has been well elucidated based on the DFT calculations. DFT calculations provide guidance that at the high reaction temperature (e.g., $723 \mathrm{~K}$ ), the catalytic cycle starting from naphthalenic cations is more inclined to increase the selectivity of ethylene than propylene (Supplementary Table 9), to our best knowledge, which has not been reported so far.

Transformation of coke to naphthalene in SAPO-34 zeolites. Two SAPO-34 zeolites with different crystal size, namely ZEOS (SAPO-34 zeolites with small average crystal size of $\sim 1 \mu \mathrm{m}$ ) and ZEOL (SAPO-34 zeolites with large average crystal size of $\sim 10$ $\mu \mathrm{m})$, are evaluated for MTO reaction in the fixed bed reactor. Xray diffraction (XRD), scanning electron microscopy (SEM), and $\mathrm{X}$-ray flurorescence $(\mathrm{XRF})$ of these two samples are shown in Supplementary Figs. 1, 2 and Supplementary Table 2. Details of sample symbols and their preparation methods used in this work can be seen in Supplementary Table 1. According to DFT calculations (Fig. 2a), in CHA cavity, naphthalenic cations are the most electrostatic stabilization at high temperature and more inclined to favor ethylene formation (Fig. 2b). Moreover, the adsorption entropy exhibits different and negative values for different intermediates (Supplementary Tables 6-8). This implies the intrinsic difference of steric stability among intermediates can be further enlarged by elevating temperature. Intuitively, the simplest way to obtain the naphthalenic cations-based catalyst is to treat the coked catalyst at a higher temperature. Compared with the results of ZEOS-Coked (ZEOS sample treated by MTO reaction at $723 \mathrm{~K}$ for $175 \mathrm{~min}$ with methanol conversion of $80 \%$ ), the proportion of naphthalene among the coke species with molecular mass smaller than $200 \mathrm{Da}$ analyzed by gas chromatography-mass spectrometer (GC-MS) is remarkably enhanced from 2 to $22 \%$ for ZEOS-Coked@N 2 (ZEOS-Coked sample treated by nitrogen at $953 \mathrm{~K}$ for $40 \mathrm{~min}$ ) (see belowunderlying mechanisms of selective transformation of coke). As shown in Supplementary Fig. 5, during the treatment by nitrogen through temperature programming, the coke amount begins slightly decreased when the temperature is above $773 \mathrm{~K}$, but it tends to stabilize after a short sweeping period at $953 \mathrm{~K}$. This confirms that coke deposited in the ZEOS-Coked@ $\mathrm{N}_{2}$ sample has already stabilized. Then, the catalytic performances of these samples are evaluated. Figure $3 \mathrm{a}$ shows the results of ZEOS sample in MTO reaction at temperature of $723 \mathrm{~K}$ and time on stream (TOS) of $124 \mathrm{~min}$ with almost full methanol conversion (named as ZEOS-124 min hereafter), achieving a peak selectivity of ethylene of $49 \%$ (Supplementary Fig. 10). For ZEOSCoked@ $\mathrm{N}_{2}$ sample, the initial ethylene selectivity in MTO reaction at TOS of $\sim 1.5 \mathrm{~min}$ significantly increases to $57 \%$ and the ethylene/propylene $(E / P)$ ratio $(\sim 1.78)$ exceeds the maximum value $(\sim 1.36)$ achieved in MTO over fresh ZEOS sample. However, compared with the results with ZEOS-Coked sample, the methanol conversion ( $75 \%)$ unfortunately shows no improvement. This may be related to the little recovery of pore volume and acidity in ZEOS-Coked@ $\mathrm{N}_{2}$ sample (shown in Fig. 4d and Supplementary Fig. 17). Interestingly, the maximum $E / P$ ratio in
MTO reaction increases dramatically from 1.03 for ZEOL-18 min (ZEOL sample treated by MTO reaction at $723 \mathrm{~K}$ for $18 \mathrm{~min}$, Supplementary Fig. 11) to 2.07 for ZEOL-Coked@N 2 (ZEOL sample treated by MTO reaction at $723 \mathrm{~K}$ for $35 \mathrm{~min}$ and then treated by nitrogen at $953 \mathrm{~K}$ for $40 \mathrm{~min}$ ), and the corresponding light olefins selectivity increases from $75 \%$ to $89 \%$ (Fig. 3b). These results are consistent with the DFT calculations, indicating that the presence of naphthalenic cations confined in CHA cavity makes the catalyst exhibits higher ethylene selectivity. However, it is practically desire to select a suitable medium to restore the catalytic conversion while keeping the dominance of naphthalenic species in the intermediates and maintaining the high ethylene selectivity.

Although air combustion can restore the catalytic activity, the introduction of aromatic $\mathrm{C}=\mathrm{O} s p^{2}$ species, on the contrary, will eventually accelerate the catalyst deactivation ${ }^{21,33}$. Hydrogen may be a potential candidate 34,35 , however, the activation energy of hydrogenation reaction of PAHs (e.g., phenanthrene) with hydrogen is very high $\left(220.47 \mathrm{~kJ} \mathrm{~mol}^{-1}\right.$, Supplementary Fig. 7a and Supplementary Table 11), thus, the hydrogenation reaction normally occurs at the elevated pressure (ca. above $1.0 \mathrm{MPa})^{34,35}$. Steam, which is the major by-product in MTO reaction, can also act as $\mathrm{H}$ and $\mathrm{OH}$ radical donor to crack the $\mathrm{C}=\mathrm{C}$ bond of aromatic rings with moderate activation energy with 110.11 and $102.43 \mathrm{~kJ} \mathrm{~mol}^{-1}$, respectively (Supplementary Fig. 7b and Supplementary Table 11). In additional, the high value-added $\mathrm{H}_{2}$ and $\mathrm{CO}$ are expected to produce during the splitting decomposition of hydroxyl-PAHs ${ }^{36}$. Therefore, steam is selected as the medium to restore the catalyst conversion.

Firstly, the effect of hydrothermal treatment on the physicochemical properties of ZEOS zeolite was studied. Results shown in Supplementary Figs. 3, 4 and Supplementary Tables 3-4 reveal that ZEOS with coke deposition has the improved hydrothermal stability (e.g., from the viewpoint of the acidity and micropore volume) than the fresh ZEOS after the same steam treatment condition ( $953 \mathrm{~K}$ for $300 \mathrm{~min}$ ). As shown in Fig. 4d, with the increase of steam cracking time, the quantity of coke decreases with the gradual recovery of micropore volume and acidity (Supplementary Figs. 4 and 17). In Fig. 4a, the proportion of naphthalene also increases with the increase of treatment time for ZEOS-Coked@N $\mathrm{N}_{2}$ samples treated by steam at $953 \mathrm{~K}$ (ZEOSCoked@ $\left.\mathrm{H}_{2} \mathrm{O}\right)$. This suggests that, though the total amount of coke decreases during steam cracking, the predominance of naphthalene can be kept. In response to this, in Fig. 3a, b, it can be observed that not only the selectivity of ethylene can be held at the high level $(\sim 60 \%)$, but also the methanol can be completely converted for both ZEOS-Coked@ $\mathrm{H}_{2} \mathrm{O}$ and ZEOL-Coked@ $\mathrm{H}_{2} \mathrm{O}$ samples. Subsequently, a commercial SAPO-34 catalyst (termed as CAT, $\sim 90 \mu \mathrm{m}$, catalyst pellet containing ZEOS, matrix and binder, Supplementary Fig. 2a) was evaluated in a micro-fluidized bed reactor at $723 \mathrm{~K}$ to examine the catalytic stability. A time independent product distribution can be observed in Fig. $3 c$, and the selectivity of light olefins can be maintained at around $88 \%$ within almost 25 min with nearly complete methanol conversion overCAT-Coked@ $\mathrm{H}_{2} \mathrm{O}-20$ min sample (CAT-Coked@N $\mathrm{N}_{2}$ sample treated by steam at $953 \mathrm{~K}$ for $20 \mathrm{~min}$ ). The selectivity of ethylene is almost maintained at 53\%, corresponding to that achieved over fresh CAT sample during MTO reaction (Supplementary Fig. 8a), which successfully avoids the ascending stage of ethylene ${ }^{23}$. That is, MTO reaction can go straight into the "optimum operation window" 1 by use of this coke transformation strategy. The influence of MTO reaction temperature on the catalytic performance was also investigated, and the results at $763 \mathrm{~K}$ are shown in Supplementary Fig. 9. As expected, the increase of MTO reaction temperature leads to a shortened catalytic lifetime and a higher $E / P$ ratio, while the selectivity of light olefins still remains 

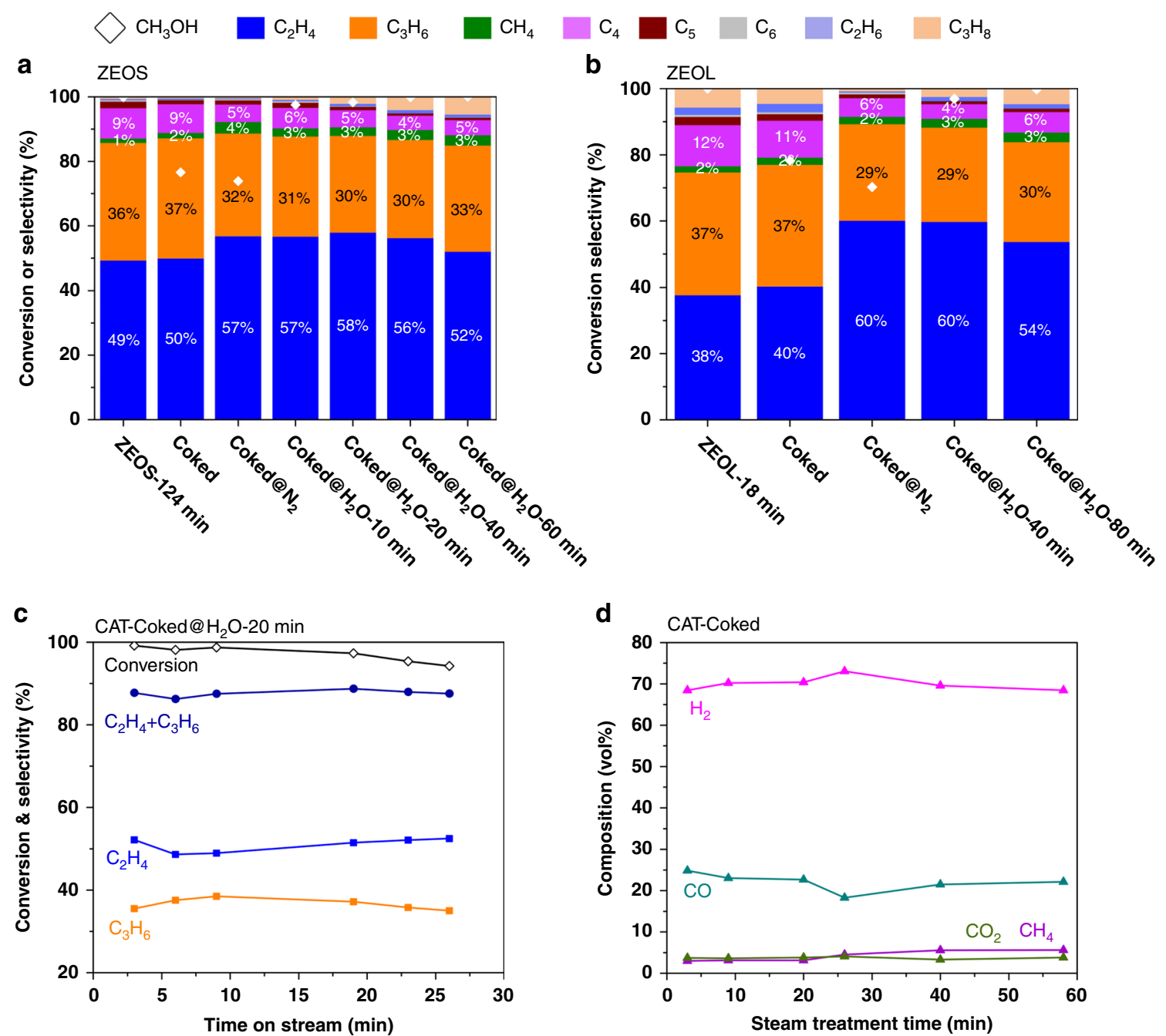

Fig. 3 Catalytic performances over naphthalene-based SAPO-34 zeolites in MTO reaction. a ZEOS and b ZEOL zeolites were used to implement the strategy of selective transformation of coke to naphthalene. MTO reactions were first performed on calcinated SAPO-34 zeolites, the peak selectivity of ethylene and product distribution under completed conversion of methanol at $124 \mathrm{~min}$ for ZEOS sample (abbreviated as ZEOS-124 min) or at 18 min for ZEOL sample (abbreviated as ZEOL-18 min) are shown in the first bar chart. When the methanol conversion decreased to $~ 80 \%$, the product distribution is shown in the second bar (samples named as ZEOS-Coked and ZEOL-Coked). The initial product distributions of MTO reaction at $\sim 1.5 \mathrm{~min}$ are shown in the followed bar charts over ZEOS-Coked and ZEOL-Coked samples treated by nitrogen at $953 \mathrm{~K}$ for 40 min (samples aliased as Coked@N $\mathrm{N}_{2}$ ) or steam cracking at $953 \mathrm{~K}$ for different times (samples aliased as Coked@ $\mathrm{H}_{2} \mathrm{O}-\mathrm{xxmin}$ series). MTO reaction condition: $T=723 \mathrm{~K}$, weight hour space velocity (WHSV)= $6.6 \mathrm{~g}_{\mathrm{MeOH}} \mathrm{g}_{\text {cat. }} \mathrm{h}^{-1}$. Steam cracking condition: $T=953 \mathrm{~K}, \mathrm{WHSV}=2.6 \mathrm{~g}_{\text {steam }} \mathrm{g}_{\text {cat. }} \mathrm{h}^{-1}$. c MTO reaction performance over the CAT-Coked@H $\mathrm{H}_{2} \mathrm{O}-20$ min sample in the fluidized bed rector. MTO reaction condition: $T=723 \mathrm{~K}, \mathrm{WHSV}=2 \mathrm{~g}_{\mathrm{MeOH}} \mathrm{g}_{\text {cat. }} \mathrm{h}^{-1}$. Steam cracking condition: $T=953 \mathrm{~K}, \mathrm{WHSV}=$ $3 \mathrm{~g}_{\text {steam }} \mathrm{g}_{\text {cat. }} \mathrm{h}^{-1}$. d Gas composition during steam cracking of CAT-Coked sample at $T=953 \mathrm{~K}$ and WHSV $=3 \mathrm{~g}_{\text {steam }} \mathrm{g}_{\text {cat. }} \mathrm{h}^{-1}$.

at $88 \%$ (Supplementary Fig. 9e). It needs to be emphasized that during steam cracking, the compositions of gas production are mainly $\mathrm{H}_{2}$ and $\mathrm{CO}$, which can reach $\sim 70$ and $\sim 20 \mathrm{vol} \%$, respectively. Notably, this effectively improves the carbon atom economy than common air combustion strategy ${ }^{1}$.

Underlying mechanisms of selective transformation of coke. Besides GC-MS, the matrix-assisted laser desorption/ionization Fourier-transform ion cyclotron resonance mass spectrometer (MALDI FT-ICR MS) was also used to obtain the complementary spectrum for the evolution of coke species ${ }^{19}$ ranged from 300 to $1600 \mathrm{Da}$ confined in CHA cavity during steam cracking, as shown in Fig. 4b. The gradual decrease in the average molecular weight mass of coke species reveals that steam can act as the active agent in hydrogenation of the coke. This is also in agreement with the decreasing maximum temperature of differential curves $\left(T_{\mathrm{G}, \max }\right)$ obtained by thermogravimetric analysis (TGA) (Supplementary
Fig. 5b), in which the $T_{\mathrm{G} \text { max }}$ can reflect the nature of coke, i.e., the higher the $T_{\mathrm{G} \text {,max }}$ the lower the $H / C$ ratio of coke ${ }^{37}$.

The vibrational fingerprints of coke species detected by operando UV-Raman characterization ${ }^{38}$ of ZEOS-Coked sample treated by steam at $923 \mathrm{~K}$ in the fixed bed reactor is shown in Fig. 4c. Normally the bands at 1630,1415 , and $1360 \mathrm{~cm}^{-1}$ are related to PAHs (e.g., naphthalene, phenanthrene, and pyrene) ${ }^{39-42}$, while the band at $1600 \mathrm{~cm}^{-1}$ corresponds to the intense $\mathrm{G}$ band of amorphous carbon ${ }^{39}$ and is overlapped with the band at $1630 \mathrm{~cm}^{-1}$. As can be seen, during steam cracking the intensities of peaks at 1630,1415 , and $1360 \mathrm{~cm}^{-1}$ decrease, indicating the elimination of PAHs. Meanwhile the appearance of the peak at $1600 \mathrm{~cm}^{-1}$ suggests the presence of amorphous carbon. And the morphology of amorphous carbon can be observed using field emission scanning electron microscopy (Supplementary Figs. 15, 16). This indicates that, although most of the coke undergoes hydrocracking during steam cracking, a part of coke is further 

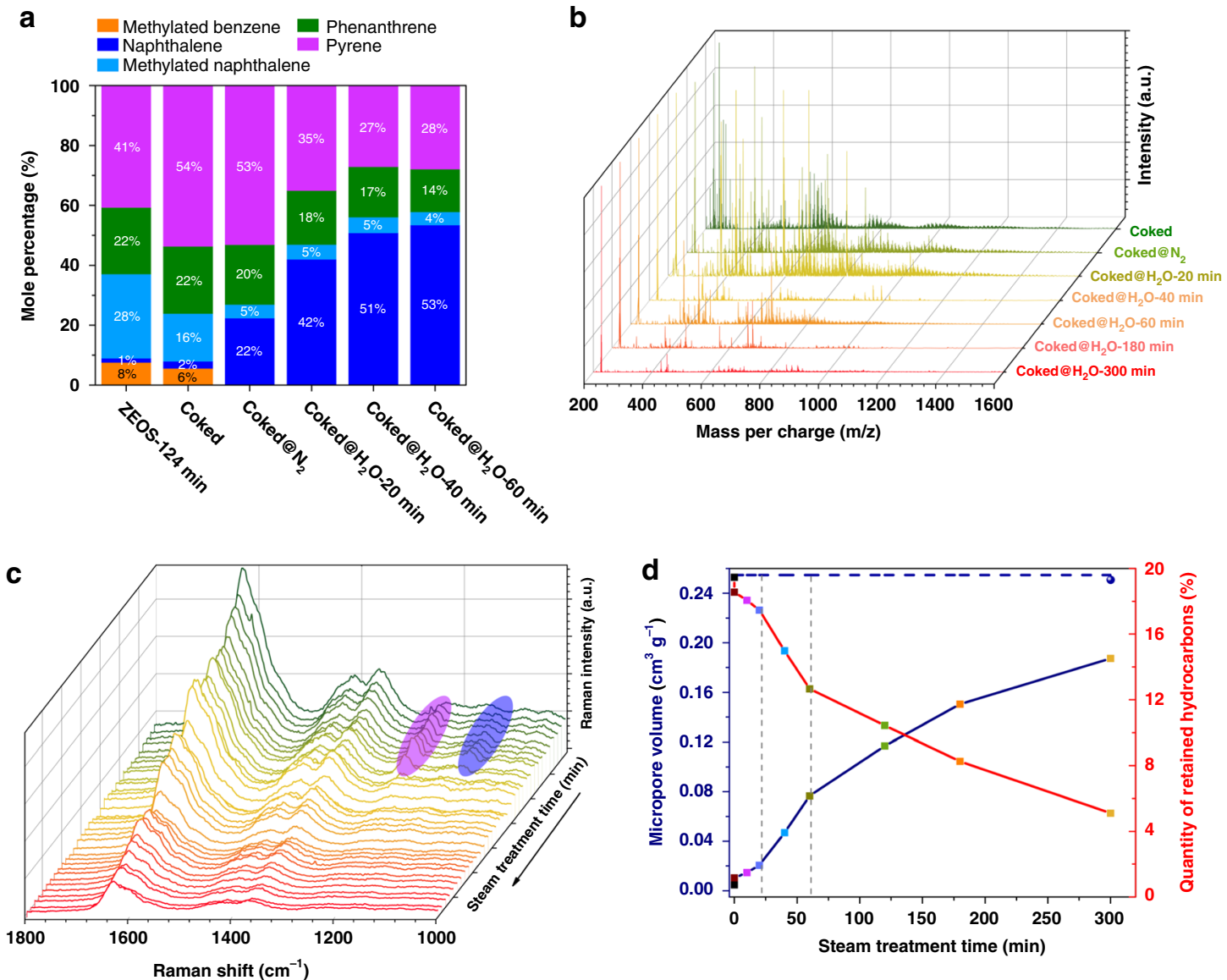

Fig. 4 Evolution of carbonaceous species and textual property of ZEOS-Coked samples. a Evolution of detailed distribution of carbonaceous intermediates with molecular mass smaller than 200 Da during nitrogen and steam cracking at $953 \mathrm{~K}$, which is analyzed by GC-MS. b Evolution of carbonaceous species with molecular mass larger than 200 Da during nitrogen and steam cracking at $953 \mathrm{~K}$, which is analyzed by MALDI FT-ICR MS. c Operando UV-Raman spectra of ZEOS-Coked samples treated by steam at $923 \mathrm{~K}$ with different time. $\mathbf{d}$ Evolution of textual property and coke quantity of ZEOS-Coked samples during steam cracking at $953 \mathrm{~K}$.

condensed, which may follow the cross-lined mechanism ${ }^{18}$. Notably, with the evolution of the steam cracking time, the band at $1630 \mathrm{~cm}^{-1}$ slowly shifts to $1640 \mathrm{~cm}^{-1}$ and band at $1360 \mathrm{~cm}^{-1}$ to $1370 \mathrm{~cm}^{-1}$, which implies that there exist transformations from PAHs, e.g., phenanthrene (Raman shift at $\sim 1365 \mathrm{~cm}^{-1}$ ) to naphthalene (Raman shift at $\sim 1380 \mathrm{~cm}^{-1}$ ). Interestingly, the bands at 1240 and $1125 \mathrm{~cm}^{-1}$, which are identified as the exocyclic aromatic with branch chains of $\mathrm{PAHs}^{41}$, appear at the initial stage of steam cracking. This observation directly testifies that ring-open process of coke species is occurred during steam cracking.

Underlying mechanisms of promotion of selectivity to ethylene. In addition to the theoretical results shown in Fig. 2, the ${ }^{12} \mathrm{C}-/{ }^{13} \mathrm{C}$-methanol switch experiments over the ZEOSCoked@ $\mathrm{H}_{2} \mathrm{O}-40$ min sample were performed to illustrate that naphthalenic species can serve as HCPs. As shown in Supplementary Figs. 12, 13a, for ZEOS-Coked@ $\mathrm{H}_{2} \mathrm{O}-40$ min sample, naphthalene is the main aromatic species while signals of methylated naphthalene species are very weak. After switching ${ }^{13} \mathrm{C}$-methanol at $723 \mathrm{~K}$ for 20,40 and $60 \mathrm{~s}$, the amount of naphthalene decreases promptly while the methylated naphthalene species increase significantly. Further MS analysis with the ${ }^{13} \mathrm{C}$ label incorporation showed (Supplementary Fig. 13b) the methyl of methylated naphthalene is mainly derived from ${ }^{13} \mathrm{C}$ - methanol. Likewise, the gas product, e.g., ethylene and propylene, are also mainly derived from ${ }^{13} \mathrm{C}$ methanol (Supplementary Fig. 13c). These results obviously prove that naphthalenic species can act as HCPs to react with methanol during MTO reaction. As shown in Fig. 3a, compared to the ZEOS-124 min sample, ZEOSCoked@ $\mathrm{H}_{2} \mathrm{O}-40$ min sample exhibits a higher ethylene selectivity, although these two samples have the nearly same coke amount (16.46 and $14.99 \mathrm{wt} \%$, Supplementary Table 5). Checking the percentage of carbonaceous intermediates in these two samples depicted in Fig. 4a, the proportion of naphthalene and methylated naphthalene in ZEOS-Coked@ $\mathrm{H}_{2} \mathrm{O}-40$ min sample (51\%) is significantly higher than that in ZEOS-124 min sample (30\%). This implies that ethylene formation, to some degree, mainly depended on the naphthalenic species rather than the coke amount. In fact, the reactivity of naphthalenic species in MTO at high temperature within CHA zeolites was previously confirmed ${ }^{10,43}$.

Besides, to investigate the influence of naphthalenic species confined within CHA cavity on the molecular diffusion, the molecular dynamics (MD) simulations were conducted. The simulated intracrystalline diffusivities $D_{\text {empty }}$ of ethylene and propylene in CHA zeolite at $723 \mathrm{~K}$ (two cavities contain one molecule) are $4.87 \times 10^{-10}$ and $8.33 \times 10^{-12} \mathrm{~m}^{2} \mathrm{~s}^{-1}$, respectively. When naphthalenic species loads within CHA cavity (two cavities contain one naphthalene molecule), the intracrystalline diffusivities $D_{\text {load }}$ of ethylene and propylene decrease to $1.46 \times 10^{-10}$ and $2.10 \times 10^{-12} \mathrm{~m}^{2} \mathrm{~s}^{-1}$, respectively. It can be found that the ratio of 
$D_{\text {empty }} / D_{\text {load }}$ of ethylene is 3.34 and the ratio of $D_{\text {empty }} / D_{\text {load }}$ of propylene is 3.97 , which implies that the diffusion limitation of propylene by the steric hindrance of naphthalenic species within $\mathrm{CHA}$ cavity is more severe than that of ethylene. Indeed, the CHA model implemented in current work only accounts for neutral species, pure silica, and rigid framework, this model would possess some limitations in the construction of force field which is important in considering the diffusion limitation owning to the steric hindrance of guest molecules. A alternative yet more accurate approach is to use the ab intio MD (AIMD) simulations 44,45 , which, however, is very time-consuming. Cnudde et al. ${ }^{44}$ compared the difference between force field MD and AIMD, and found that, despite the values of free energy barriers were quantitatively different, the qualitative trends of these two methods were similar. In this sense, the $D_{\text {empty }} / D_{\text {load }}$ ratios derived from force field $\mathrm{MD}$, which are 3.34 for ethylene and 3.97 for propylene, can qualitatively reflect that the diffusion limitation of propylene by the steric hindrance of naphthalene species within CHA cavity is more severe than that of ethylene. Based on the above experiments and theoretical calculations, we can find that the naphthalenic species confined within $\mathrm{CHA}$ cavity not only serve as the HCPs to preferential formation of ethylene but also further limits the diffusion of large molecules, e.g., propylene. This synergic effect imposed by naphthalenic species can promote the selectivity of ethylene.

Structured illumination microscopy (SIM) was used to resolve the location of carbonaceous species for ZEOL samples. According to the previous experimental work ${ }^{46-48}$ and theorical calculations ${ }^{49-51}$, the excitation wavelengths of $\mathrm{B}_{\mathrm{n}}{ }^{+}, \mathrm{N}_{\mathrm{n}}{ }^{+}$, $\mathrm{PH}_{\mathrm{n}}{ }^{+}$, and $\mathrm{PYR}_{\mathrm{n}}{ }^{+}$are situated around 390, 480, 560, and $640 \mathrm{~nm}$, respectively, and the corresponding emission wavelengths are located in the range of 480-490, 500-520, 620-630, and $670-700 \mathrm{~nm}$, respectively. The wavelengths of illumination and emission detection of SIM used in this work are 405 (detection at $435-485 \mathrm{~nm}$ ), 488 (detection at 500-545 nm), 561 (detection at $570-640 \mathrm{~nm}$ ), and $640 \mathrm{~nm}$ (detection at $663-738$ $\mathrm{nm})$, respectively, which can cover the characteristic area of excitation and emission wavelengths of $\mathrm{B}_{n}{ }^{+}, \mathrm{N}_{\mathrm{n}}{ }^{+}, \mathrm{PH}_{\mathrm{n}}{ }^{+}$, and $\mathrm{PYR}_{\mathrm{n}}{ }^{+}$. SIM images shown in Fig. 5a clearly elucidate that for ZEOL-Coked sample, the $\mathrm{PH}_{n}{ }^{+}$and $\mathrm{PYR}_{\mathrm{n}}{ }^{+}$mainly locate at the crystal rim and center. And these species located at the crystal rim can block the micropore (Fig. 4d) and hamper the accessibility of activated intermediates (e.g., $\mathrm{N}_{\mathrm{n}}{ }^{+}$) and acid sites inside crystal to the methanol, causing catalyst deactivation. In Fig. 5b, after treatment by nitrogen at $953 \mathrm{~K}$ for $40 \mathrm{~min}$, the relative fluorescence intensity of $\mathrm{N}_{\mathrm{n}}{ }^{+}$increases substantially at especially the crystal rim while the relative intensity of $\mathrm{PH}_{n}{ }^{+}$ and $\mathrm{PYR}_{\mathrm{n}}{ }^{+}$decreases. When this sample is evaluated at $723 \mathrm{~K}$ for MTO reaction as shown in Fig. $5 \mathrm{e}, \mathrm{N}_{\mathrm{n}}+$ deposited at the crystal rim is further transformed into the $\mathrm{PH}_{\mathrm{n}}{ }^{+}$and $\mathrm{PYR}_{\mathrm{n}}{ }^{+}$. Interestingly, in Fig. $5 c$, the relatively homogeneous distribution of carbonaceous species throughout the ZEOLCoked@ $\mathrm{H}_{2} \mathrm{O}-40$ min crystal is revealed. Here the increased fluorescence intensity of $\mathrm{N}_{\mathrm{n}}{ }^{+}$corresponds to the promotion in naphthalene concentration, which is also shown in Fig. 4a. Unlike the distribution of carbonaceous species over ZEOLCoked sample performed by original MTO reaction (Fig. 5a), the uniform spatial distribution of carbonaceous species over the ZEOL-Coked@ $\mathrm{H}_{2} \mathrm{O}-40$ min sample after MTO reaction can be observed in Fig. $5 \mathrm{f}$. After a long time $(350 \mathrm{~min})$ of steam cracking, the residual amorphous carbon (Supplementary Fig. 16) is mainly concentrated at the crystal rim (Fig. 5d). As shown in Fig. $5 \mathrm{~g}$, due to the hindrance of amorphous carbon, the formation of coke species interior SAPO-34 crystal is limited. This diffusion limitation imposed by the amorphous carbon can also be beneficial to improve the initial selectivity of ethylene, while the catalyst lifetime slightly reduces compared with the fresh ZEOL crystal (Supplementary Fig. 11e).

Coke transformation strategy implemented in a pilot plant. To attain a reproducible behavior, the coke transformation strategy is evaluated in a fluidized bed reactor-regenerator pilot plant by use of CAT catalyst. The diameters of reactor and regenerator are both $0.124 \mathrm{~m}$, and the corresponding temperatures of MTO reaction and steam cracking are 743 and $953 \mathrm{~K}$ for reactor and regenerator, respectively. The schematic diagram and photo of pilot plant are shown in Supplementary Figs. 18, 19. The experimental catalyst circulation rate is $1.2 \mathrm{~kg} \mathrm{~h}^{-1}$. For comparison, we also used air combustion as the regeneration manner to recover the catalyst activity under the same reaction and regeneration temperatures. The light olefins selectivity was $79 \%$ in the pilot facility under complete regeneration by air. The corresponding $E / P$ ratio was 1.36 (Fig. 6). Implementing the coke transformation strategy with steam cracking to the same reactionregeneration configuration, the light olefins selectivity can reach $83 \%$ at methanol conversion of $98 \%$ (Fig. 6a) and $85 \%$ at methanol conversion of $95 \%$ (Fig. 6b). Concomitantly, the $E / P$ ratio increases to 1.44 and 1.54 , respectively, while the selectivity of propylene remains almost unchanged. The incompletely converted methanol can be separated from gas product and recycled to MTO reactor. Supplementary Fig. 20 shows the composition of flue gas from regenerator, in which only $5 \mathrm{vol} \% \mathrm{CO}_{2}$ is achieved and $\mathrm{H}_{2}$ and $\mathrm{CO}$ accounts to $88 \mathrm{vol} \%$. The results under the industrial-alike continuous operation suggest that the proposed coke transformation strategy can significantly promote the formation of light olefins and reduce $\mathrm{CO}_{2}$ emissions, bursting the economics and sustainability of MTO process. Considering methanol can readily reach the complete conversion in MTO reaction, and it might be possible that the different ethylene selectivity is due to the excess of zeolite which may reconvert part of the olefins into side products. To this end, we have conducted several experiments in our pilot plant to compare the performance of the air-treated and steam-treated samples at the (almost) same methanol conversion $(\sim 95 \%)$ and similar coke content on catalyst at the reactor inlet (air-treated sample: $7.36 \mathrm{wt}$ $\%$, steam-treated sample: $7.15 \mathrm{wt} \%$ ). The results are shown in Supplementary Fig. 21. Expectedly, an ethylene selectivity of $\sim 51 \%$ has been achieved over steam-treated sample, which is higher than that over air-treated sample ( 48\%). At such a lower methanol conversion, the influence of excess zeolite can be excluded. However, though the methanol conversion and coke content no doubt are two most important parameters influencing MTO reaction, the back mixing of catalysts and gas will also affect ethylene selectivity to a minor extent because our experiments have been carried out in a fluidized bed reactor-regenerator pilot plant with catalyst circulation. Anyway, from the results of Supplementary Fig. 21, the effects of conversion and coke amount on the ethylene selectivity can be decoupled, and it testified again that steam treatment strategy proposed in this work is more conducive to ethylene formation than conventional air treatment strategy.

\section{Discussion}

We propose a feasible strategy to enhance the ethylene selectivity and carbon atom utilization during MTO reaction by selectively transforming coke species to active carbonaceous intermediates (naphthalenic cations) via steam cracking, which has been verified in both the laboratory-scale reactor and fluidized bed reactor-regenerator pilot plant. With the aid of DFT calculations, together with multiple spectroscopy techniques, e.g., GC-MS, MALDI FT-ICR MS, operando UV-Raman spectra and SIM, the 

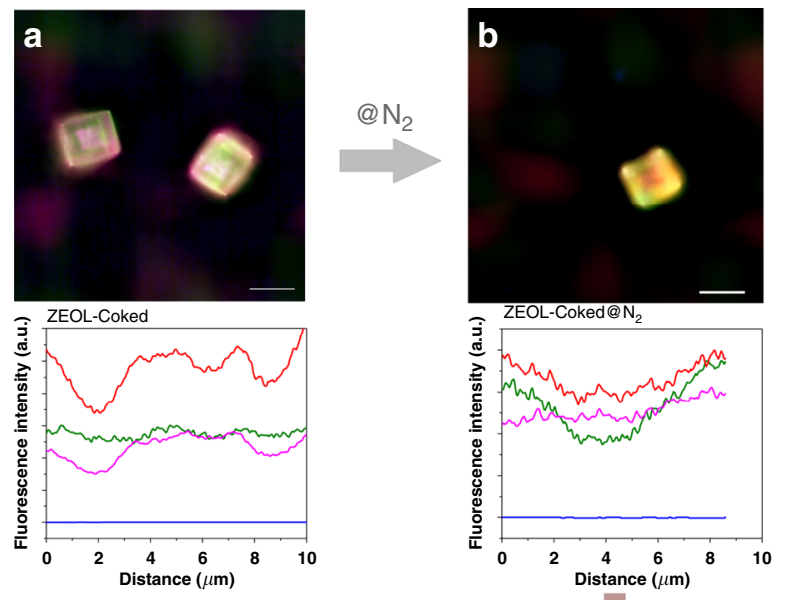

MTO
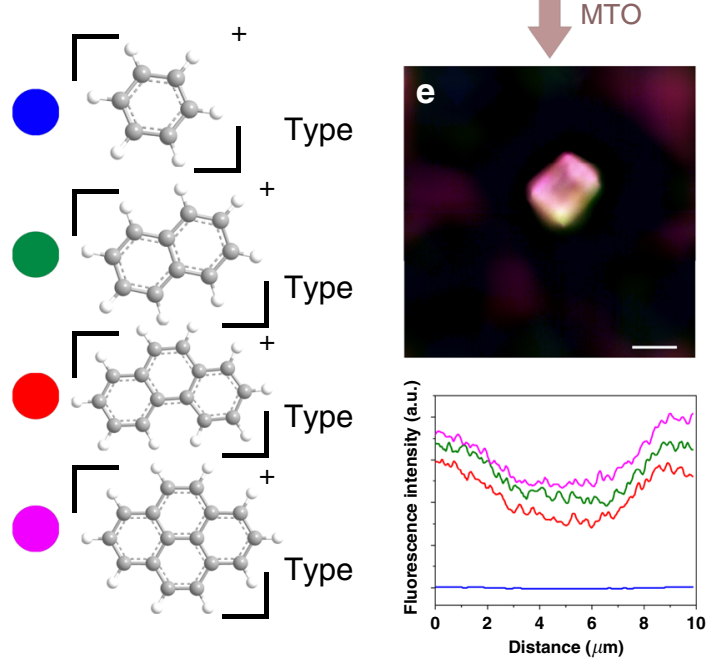
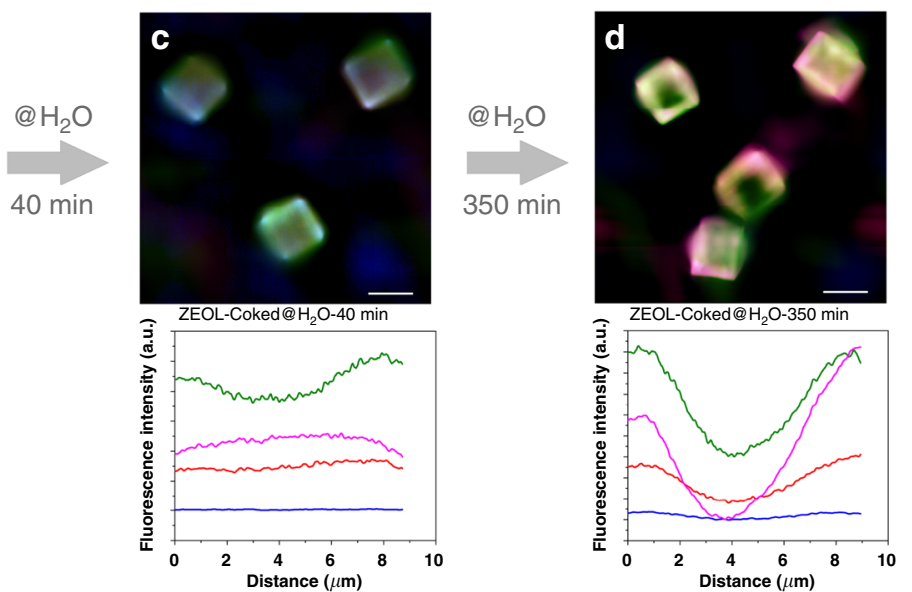

MTO
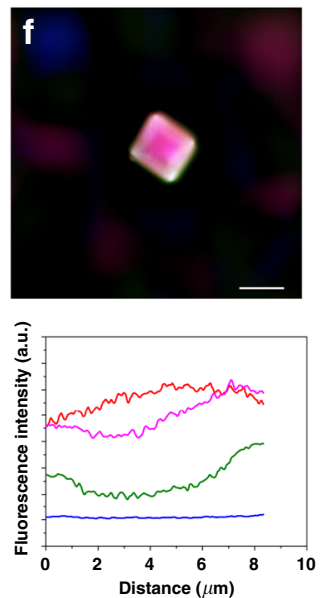
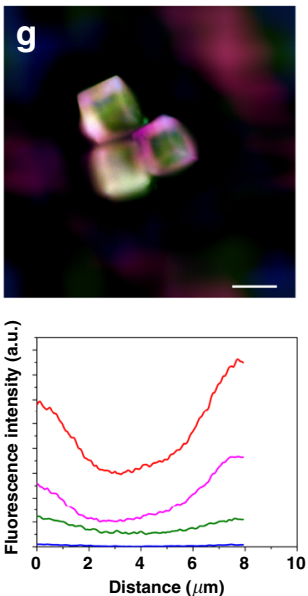

Fig. 5 Spatiotemporal evolution of carbonaceous intermediates confined in ZEOL zeolites. a ZEOL-Coked sample. b ZEOL-Coked@N $\mathrm{N}_{2}$ sample. c ZEOLCoked@ $\mathrm{H}_{2} \mathrm{O}-40$ min sample d ZEOL-Coked@ $\mathrm{H}_{2} \mathrm{O}-350$ min sample.e-g Deactivated samples of ZEOL-Coked@N $\mathrm{Z}_{2}, \mathrm{ZEOL}-\mathrm{Coked@H}_{2} \mathrm{O}-40$ min and ZEOLCoked@ $\mathrm{H}_{2} \mathrm{O}-350$ min used for MTO reaction, respectively. Scale bar represents $10 \mu \mathrm{m}$. The SIM images shown is the fluorescence that originated from the overlap of four profiles with a laser excitation of $405 \mathrm{~nm}$ (detection at $435-485 \mathrm{~nm}$, false color: blue), $488 \mathrm{~nm}$ (detection at $500-545 \mathrm{~nm}$, false color: green), $561 \mathrm{~nm}$ (detection at 570-640 nm, false color: red), $640 \mathrm{~nm}$ (detection at 663-738 nm, false color: pink).
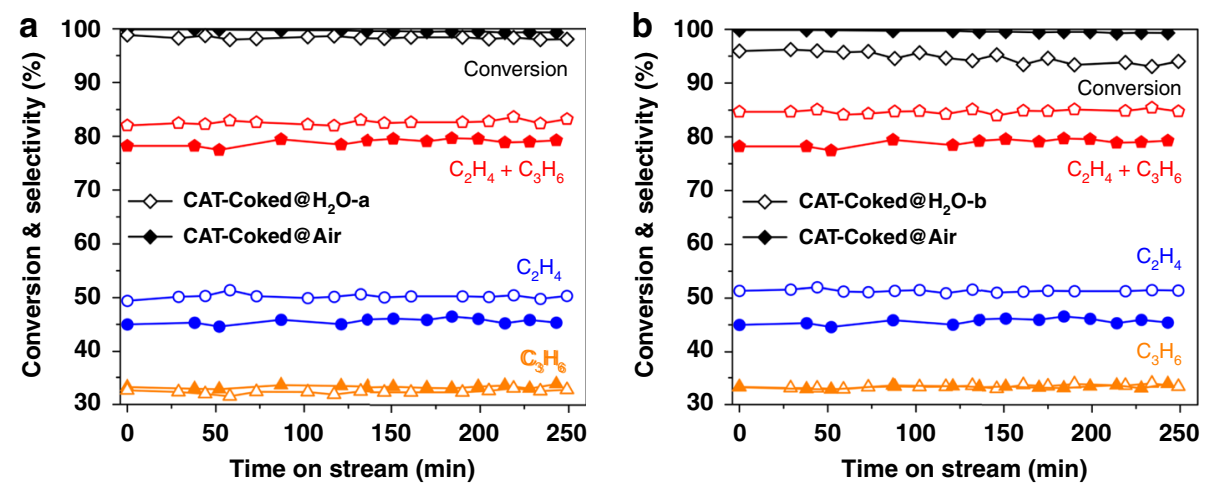

Fig. 6 Implementing the coke transformation strategy over CAT catalysts in a pilot plant. a MTO reaction performances over the CAT-Coked sample completely regenerated by air combustion at $953 \mathrm{~K}$ (abbreviated as CAT-Coked@Air) and treated by steam at $953 \mathrm{~K}$ with the water feed of $500 \mathrm{~g} \mathrm{~h}-1$ (abbreviated as CAT-Coked@ $\mathrm{H}_{2} \mathrm{O}-\mathrm{a}$ ).b MTO reaction performances over the CAT-Coked@Air sample and CAT-Coked sample treated by steam at $953 \mathrm{~K}$ with the water feed of $300 \mathrm{~g} \mathrm{~h}^{-1}$ (abbreviated as CAT-Coked@ $\mathrm{H}_{2} \mathrm{O}-\mathrm{b}$ ).

steric stability and catalytic functionality of naphthalenic cations, profound insights of transformation of coke are depicted. Naphthalenic species, confined within CHA cavity not only serve as the active HCPs but also further limit the diffusion of large molecules. This synergic effect imposed by naphthalenic species promotes the selectivity of ethylene. This strategy is much more competitive than current commercial MTO process, with regards to the unexpectedly high light olefins selectivity and low $\mathrm{CO}_{2}$ 
emission. Especially the latter can avoid the emission of greenhouse gas and prevent significant loss of carbon in terms of atom economics. Given the fact that many heterogeneous catalytic reactions are autocatalytic, we expect that this established strategy will also be of high instructive for other heterogeneous catalytic processes.

\section{Methods}

Computational details. All density functional theory (DFT) calculations were performed with the Gaussian 09 package ${ }^{52}$. Three $36 \mathrm{~T}$ cluster models representing the structure of CHA zeolite are used to calculate the adsorption energies. Specifically, these three $36 \mathrm{~T}$ cluster models are respectively $\left(\mathrm{Al}_{18} \mathrm{P}_{17} \mathrm{SiO}_{54} \mathrm{H}_{36}\right)$ representing the negative SAPO-34 zeolite model, $\left(\mathrm{Si}_{36} \mathrm{O}_{54} \mathrm{H}_{36}\right)$ representing neutral pure silica model of CHA cavity, and $\left(\mathrm{Al}_{18} \mathrm{P}_{17} \mathrm{SiO}_{54} \mathrm{H}_{37}\right)$ representing SAPO-34 zeolite model containing one Brønsted acid site. These structures were extracted from the periodic structures of CHA. For the extended zeolite model, the terminal $\mathrm{Al}-\mathrm{H}$ or $\mathrm{Si}-\mathrm{H}$ was fixed at a bond length of $1.54 \AA$ and oriented along the direction of the corresponding $\mathrm{Al}-\mathrm{O}$ or $\mathrm{Si}-\mathrm{O}$ bond. Except $\mathrm{H}$ atom of Brønsted acid site, all other $\mathrm{H}$ atoms were fixed. In all these three cluster models, $\mathrm{Al}, \mathrm{P}, \mathrm{Si}$, and $\mathrm{O}$ atoms were fully optimized without restrictions. Following the work ${ }^{8,11,45}$, the calculations of adsorption energies based on DFT using the $\omega$ B97XD and 6-31G (d, p) basis set were conducted. For the calcualtion of adsorption energies, the benzenic $\left(\mathrm{B}_{\mathrm{n}}^{+}\right)$, naphthalenic $\left(\mathrm{N}_{\mathrm{n}}{ }^{+}\right)$, phenanthrenic $\left(\mathrm{PH}_{\mathrm{n}}{ }^{+}\right)$, and pyrenic $\left(\mathrm{PYR}_{\mathrm{n}}{ }^{+}\right)$carbocations with $n$ methyl substituent were first loaded within negative SAPO-34 zeolite model and neutral pure silica model of CHA cavity, and the corresponding calculated adsorption energies are listed in Supplementary Tables 6 and 7, respectively. The neutral benzene $\left(\mathrm{B}_{\mathrm{n}}\right)$, naphthalene $\left(\mathrm{N}_{\mathrm{n}}\right)$, phenanthrene $\left(\mathrm{PH}_{\mathrm{n}}\right)$, and pyrene $\left(\mathrm{PYR}_{\mathrm{n}}\right)$ species with $n$ methyl substituent were then loaded within neutral SAPO-34 model containing one Bronsted acid site for calculating the adsorption energies as listed in Supplementary Table 8. The verification of calculated approach is introduced in the Supplementary Information. In this work, we focus on the effect of framework topology rather than framework composition or flexibility 45,53 on the preferential stabilization of carbenium ions within $\mathrm{CHA}$, and therefore the cluster models were employed in our current work.

For the calculation of transition state, an extended $74 \mathrm{~T}\left(\mathrm{SiP}_{36} \mathrm{Al}_{37} \mathrm{O}_{119} \mathrm{H}_{59}\right)$ cluster model extracted from the crystallographic $\mathrm{CHA}$ structure represents the structure of neutral SAPO-34 model containing one Brønsted acid site as shown in Supplementary Fig. $6 \mathrm{a}^{54}$. For the extended model, the terminal Al-H and P-H were fixed and oriented along the direction of the corresponding $\mathrm{Al}-\mathrm{O}$ and $\mathrm{P}-\mathrm{O}$ bond. The location of acid site was chosen at the 8-membered ring, accessible for adsorbents and surrounded by maximum reaction space. To preserve the integrity of the crystalline structure, the 8-membered ring, active center $(\mathrm{SiO})_{3}-\mathrm{Si}-\mathrm{OH}-\mathrm{Al}-$ $(\mathrm{SiO})_{3}$ and the adsorbate were set to high-level layer while the rest of atoms were set to low-level layer. The combined theorical ONIOM method was exploited to the prediction of stability of various adsorption structure and geometries of and transition states (TS). For the structure optimization, $\omega$ B97XD hybrid density function ${ }^{55}$ with $6-31 \mathrm{G}(\mathrm{d}, \mathrm{p})$ basis sets and semi-empirical AM1 were employed for optimization of structure of high-level and low-level layer, respectively. To obtain high accurate interaction energy, the single-point energies were calculated at the level of $\omega \mathrm{B} 97 \mathrm{XD} / 6-31 \mathrm{G}(\mathrm{d}, \mathrm{p})$ on the basis to of optimized structure. The frequency calculations were performed at the same level as geometry optimizations to check whether the saddle point exhibits the proper number of imaginary frequencies. The attained transition state is a first-order saddle point of potential energy surface, with only a single imaginary frequency. The adsorbed state is verified as being situated in the energy minima points of potential energy surface, with only real frequency. The intrinsic free energy was obtained from the $\omega \mathrm{B} 97 \mathrm{XD} / 6-31 \mathrm{G}(\mathrm{d}, \mathrm{p})$ total electronic energies and the thermal correction from the $\omega \mathrm{B} 97 \mathrm{XD} / 6-31 \mathrm{G}(\mathrm{d}$, p): AM1 frequency calculations with the correction of zero-point vibration energies. The noncovalent interaction index approach was adopted to visualize the noncovalent interactions between the adsorbate and zeolite framework ${ }^{56}$.

The isosurface plots of the reduced density gradient (RDG) were obtained by calculating the RDG functions, defined as $\operatorname{RDG}(r)=1 /\left(2\left(3 \pi^{2}\right)^{1 / 3}\right)|\nabla \rho(r)| /\left(\rho(r)^{4 / 3}\right)$ ( $\rho$ represents the electron density) and the quantity $\operatorname{sign}\left(\lambda_{2}\right) \rho\left(\operatorname{sign}\left(\lambda_{2}\right) \rho<0, \mathrm{H}\right.$ bonding interaction; $\operatorname{sign}\left(\lambda_{2}\right) \rho \approx 0$, weak van der Waals interaction; $\operatorname{sign}\left(\lambda_{2}\right) \rho>0$, strong repulsive interaction) by the Multiwfn software ${ }^{57}$

The molecular diffusivities were obtained from molecular dynamics (MD) simulations. MD simulations were carried out using the Materials Studio simulation package (Accelrys Software). The adsorption of molecules in CHA structure were performed using the grand canonical Monte Carlo (GCMC) simulation method. Periodic boundary conditions were applied in all three directions. The interatomic interactions were described by the condensed-phaseoptimized molecular potentials for atomistic simulation studies (COMPASS) force field. The applicability of the used force field was checked in the previous work ${ }^{51}$. The Ewald \& Group summation method has an Ewald accuracy of $10^{-5} \mathrm{kcal} \mathrm{mol}^{-1}$ when it is used for calculating electrostatic potential energy. To achieve an equilibrium state, $10^{7}$ Monte Carlo steps were carried out. The zeolitic framework with a rigid structure was considered. The metropolis scheme was used at a constant loading and constant temperature. To minimize the energy of constructed structures, all the structures were equilibrated by five anneal cycles from 250 to
$750 \mathrm{~K}$ with a heating ramp of five to refine the conformation. Dynamics processes in the NVT ensemble, i.e., the number of particles (N), volume (V), and temperature $(\mathrm{T})$ as the constants, were performed for 10,000 ps in $10,000,000$ steps for ethylene and 20,000 steps in 20,000,000 steps for propylene $723 \mathrm{~K}$. The velocity Verlet algorithm was used to integrate the Newton's equations of motion with a time step of $1 \mathrm{fs}$. A cutoff radius of $18.5 \AA$ was assumed for Lennard-Jones interaction potential calculation. The simulated temperature was controlled by a Nosé thermostat. The structures considered in this study and the mean square displacement (MSD) of ethylene and propylene are shown in Supplementary Fig. 14. The slope of MSD as a function of time was used to determine the selfdiffusivity following Einstein relation: ${ }^{58}$

$$
\operatorname{MSD}(\tau)=2 n D \tau+b
$$

where $n$ is the dimension of framework $(n=1,2$, and 3 for $1 \mathrm{D}, 2 \mathrm{D}$, and $3 \mathrm{D}$ frameworks, respectively) and $b$ the thermal factor arising from atomic vibrations.

Catalyst preparation. Commercial shaped SAPO-34 catalyst (CAT), which contains catalytically active SAPO-34 zeolites dispersed in the matrix and binder, and corresponding SAPO-34 zeolites (ZEOS) under study were purchased from Catalyst \& Catalysis Technology Co. Ltd. of CAS. The synthesis procedures of the SAPO-34 zeolites with large crystal size (ZEOL) were taken from existing recipes from the open literature $\mathrm{e}^{59}$.

Catalyst characterization. The powder XRD patterns were recorded on a PANalytical X' Pert PRO X-ray diffractometer with $\mathrm{Cu}-\mathrm{K}_{\alpha}$ radiation $(\lambda=1.54059 \AA)$, operating at $40 \mathrm{kV}$ and $30 \mathrm{~mA}$. XRD patterns were recorded in the range of $2 \theta$ $=5-40^{\circ}$.

The quantitative elemental analysis was determined by XRF spectrometer (Philips, Magix-601).

The morphology and crystal size of SAPO-34 samples used in this work were observed by scanning electron microscopy (Hitachi TM3000). The morphology of insoluble carbonaceous species was obtained by Field emission scanning electron microscopy (FESEM, Hitachi SU8020).

Temperature-programmed desorption of ammonia $\left(\mathrm{NH}_{3}-\mathrm{TPD}\right)$ was measured on a Micrometric 2920 chemical adsorption instrument to enumerate the acid site density of the SAPO-34 samples. Firstly, sample was loaded into a quartz U-shaped reactor and pretreated at $873 \mathrm{~K}$ for $1 \mathrm{~h}$ under helium atmosphere. Then, the sample was cooled to $373 \mathrm{~K}$ and saturated with $\mathrm{NH}_{3}$. Lastly, $\mathrm{NH}_{3}-\mathrm{TPD}$ was carried out in a constant flow of helium atmosphere $\left(20 \mathrm{~mL} \mathrm{~min}^{-1}\right)$ from 373 to $873 \mathrm{~K}$ at a heating rate of $10 \mathrm{~K} \mathrm{~min}^{-1}$

The nitrogen adsorption-desorption measurements were conducted with Micromeritics ASAP 2020 at $77 \mathrm{~K}$ after SAPO-34 samples degassed at $623 \mathrm{~K}$ under vacuum for $6 \mathrm{~h}$ to obtain their textural properties.

The coke contents of SAPO-34 samples were measured by thermo-gravimetric analysis (TGA) carried out on a SDTQ 600 setup at the temperature range of $323-1173 \mathrm{~K}$ with a heating rate of $15 \mathrm{~K} \mathrm{~min}^{-1}$ under an air flow of $100 \mathrm{~mL} \mathrm{~min}^{-1}$ The coke content is defined as the quantity of carbonaceous species in per unit mass of calcined catalyst and the loss of mass between 573 and $1173 \mathrm{~K}$ measured by TGA was used to estimate the coke content.

Gas chromatography-mass spectrometry (GC-MS) and matrix-assisted laser desorption ionization Fourier-transform ion cyclotron resonance (MALDI FTICR) MS were used to identify the carbonaceous species. Fifteen milligram of the coked SAPO-34 sample was dissolved in $1 \mathrm{~mL} 20 \mathrm{wt} \%$ hydrofluoric acid in a Teflon container. The organic compounds were extracted by the addition of 1 $\mathrm{mL}$ dichloromethane containing $100 \mathrm{ppm}$ hexachloroethane as internal standard. The organic components in extracted phase with molecular weight smaller than 200 were analyzed by GC-MS equipped with a HP- 5 capillary column and FID detector. Then, the extracted phase was mixed with 1,8,9 anthracenetriol (dithranol) matrix. Lastly, $1 \mu \mathrm{L}$ of the mixture was taken to spot on the sample holder. The 15-T FT-ICR MS (Bruker Daltonics, Bremen, Germany) equipped with a Nd: YAG laser emitting $355 \mathrm{~nm}$ laser to generate ions and a time-of-flight mass analyzer in reflection mode was used to record MS signals. Ion source parameters were optimized to a broadband range $(150<\mathrm{m} / \mathrm{z}$ $<2000$ ), which allowed the analysis of carbonaceous species with molecular weight greater than $200 \mathrm{Da}$.

Diffuse reflectance infrared Fourier transform spectroscopy (DRIFT) spectra were collected on a Bruker Vextex 27 spectroscope supplied with MCT detector ${ }^{60}$ For each experiment, the same quantity of SAPO-34 sample was preheated in nitrogen atmosphere at $623 \mathrm{~K}$ for $1 \mathrm{~h}$ in the diffuse reflectance infrared cell with $\mathrm{ZnSe}$ window to remove adsorbed water. The absorption spectra were obtained by collection 16 scans at $4 \mathrm{~cm}^{-1}$ resolution at $623 \mathrm{~K}$.

MTO reaction and steam cracking. To remove the organic template, all SAPO-34 samples were firstly calcinated at $873 \mathrm{~K}$ for $6 \mathrm{~h}$. In MTO reaction, the mass ratio of water to methanol in the feed was 0.2 . ZEOS zeolite was pressed into flakes without binder at $10 \mathrm{MPa}$, and then crushed into pellets and sieved to a diameter of 250-425 $\mu \mathrm{m}$. To keep the intact morphology of ZEOL for subsequent use in structured illumination microscopy, the prilling of ZEOL zeolite was not implemented. Then MTO reactions over ZEOS and ZEOL zeolites with loading of 0.100 
$\mathrm{g}$ were carried out in a quartz tubular fixed bed reactor with the inner diameter of $0.004 \mathrm{~m}$ under atmospheric pressure with the weight hour space velocity (WHSV) of $6.6 \mathrm{~g}_{\mathrm{MeOH}} \mathrm{g}_{\text {cat. }}{ }^{-1} \mathrm{~h}^{-1}$ at $723 \mathrm{~K}$. When the methanol conversion decreased to $\sim 80 \%$, under the sweeping of nitrogen atmosphere, ZEOS and ZEOL samples deposited with coke (ZEOS-Coked and ZEOL-Coked) were heated at a rate of $5 \mathrm{~K}$ $\mathrm{min}^{-1}$ to $953 \mathrm{~K}$ and aged for $40 \mathrm{~min}$ (ZEOS-Coked@N $\mathrm{N}_{2}$ and ZEOL-Coked@ $\mathrm{N}_{2}$ ). Then ZEOS-Coked@ $\mathrm{N}_{2}$ and ZEOL-Coked@N $\mathrm{N}_{2}$ samples were treated by steam at $953 \mathrm{~K}$ (ZEOS-Coked@ $\mathrm{H}_{2} \mathrm{O}$ and ZEOL-Coked@ $\mathrm{H}_{2} \mathrm{O}$ ) for different times with WHSH of $2.6 \mathrm{~g}_{\text {steam }} \mathrm{g}_{\text {cat. }}{ }^{-1} \mathrm{~h}^{-1}$. Subsequently, these samples were cooled to $723 \mathrm{~K}$, and MTO reactions were catalyzed with the same WHSV, i.e., $6.6 \mathrm{~g}_{\mathrm{MeOH}} \mathrm{g}_{\text {cat. }}{ }^{-1}$ $\mathrm{h}^{-1}$, and composition of reactant feed.

MTO reaction over CAT catalyst was carried out in a micro fluidized bed with an inner diameter of $0.019 \mathrm{~m}$ and a height of $0.35 \mathrm{~m}$ under atmospheric pressure with the WHSV of $2 \mathrm{~g}_{\mathrm{MeOH}} \mathrm{g}_{\text {cat }}{ }^{-1} \mathrm{~h}^{-1}$ at 723 or $763 \mathrm{~K}$, and $5.0 \mathrm{~g}$ of CAT catalyst was loaded into the reactor. When MTO reaction proceeded for a period of time and the methanol conversion was less than $100 \%$. Similarly, under the sweeping of nitrogen atmosphere, the CAT catalyst deposited with coke (CAT-Coked) was heated at a rate of $5 \mathrm{~K} \mathrm{~min}^{-1}$ to $953 \mathrm{~K}$ and aged for $40 \mathrm{~min}$ (CAT-Coked@ $\mathrm{N}_{2}$ ). Then the CAT-Coked@ $\mathrm{N}_{2}$ sample was treated by steam at $953 \mathrm{~K}$ (CAT-Coked@ $\mathrm{H}_{2} \mathrm{O}$ ) for different times, i.e., $5,10,20$, and $180 \mathrm{~min}$, with WHSV of $3.0 \mathrm{~g}_{\text {steam }} \mathrm{g}_{\text {cat. }}{ }^{-1} \mathrm{~h}^{-1}$. Subsequently, these samples were cooled to 723 or $763 \mathrm{~K}$, and MTO reactions were catalyzed with the same WHSV and composition of reactant feed.

The diameters of fluidized bed reactor and regenerator in the circulating configuration were both $0.124 \mathrm{~m}$, experimental catalyst circulation rate is $1.2 \mathrm{~kg} \mathrm{~h}^{-1}$. The temperatures of MTO reaction and steam cracking were 743 and $953 \mathrm{~K}$, respectively. Note, the liquid flow of methanol (99.5\% purity) or deionized water was passed through a vaporizer before entering the reactor to guarantee well vaporization of liquid feed.

The effluent products of MTO reaction and steam cracking were analyzed by an online Agilent 7890 A GC equipped with two detectors. The organic compositions were monitored using a Plat-Q capillary column connected to a flame ionization detector (FID) and the $\mathrm{CO}, \mathrm{CO}_{2}$, and $\mathrm{H}_{2}$ were determined suing a TDX-01 packed column connected to a thermal conductivity detector (TCD). The methanol conversion and olefins selectivity were calculated on $\mathrm{CH}_{2}$ basis. Dimethyl ether (DME) was considered as reactant in the calculation.

Operando UV-Raman spectra. Operando UV-Raman spectra was collected using a home-build spectrometer ${ }^{38}$. The system was composed of a $257 \mathrm{~nm}$ constant-wave laser, a $25 \mathrm{~mm}$ diameter off-axis parabolic mirror as the lightcollecting element, an edge filter to filter Rayleigh scattered light, a spectrograph, and a UV-CCD camera produced by Andor. All spectra were calibrated by placing the main Raman peak of monocrystalline $S i$ at $520 \mathrm{~cm}^{-1}$. To ensure optical throughput, the slit width was set at $150 \mu \mathrm{m}$, resulting in a spectral resolution of $\sim 7 \mathrm{~cm}^{-1}$. For most experiments, the laser power at the sample was kept below $2 \mathrm{~mW}$ to prevent burning effects. The typical accumulation time per spectrum was $\sim 30 \mathrm{~s}$. For operando UV-Raman experiments, $10 \mathrm{mg}$ of the ZEOSCoked sample were treated by steam at $923 \mathrm{~K}$ for $2 \mathrm{~h}$, the WHSV was of 2.0 $\mathrm{g}_{\text {Steam }} \mathrm{g}_{\text {cat. }}{ }^{-1} \mathrm{~h}^{-1}$

Structured illumination microscopy (SIM). SIM was applied to gain superresolution images on the spatiotemporal distribution of the coke species located in ZEOL series samples. The super-resolution imaging was carried out using a Nikon $\mathrm{N}$-SIM super-resolution microscopy system with a motorized inverted microscopy ECLIPSE Ti2-E, a 100×/NA 1.49 oil immersion TIRF objective lens (CFI HP) and

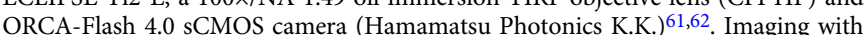
$405,488,561$, and $640 \mathrm{~nm}$ multilaser light sources, the emissions by excitation were collected with four photomultiplier tubes in the range 435-485, 500-545, 570-640, $663-738 \mathrm{~nm}$ for the four lasers, respectively. Imaging was performed under ex-situ condition at room temperature. ZEOL series samples were loaded on glassbottomed culture dishes $(35 \mathrm{~mm}$ dish with $20 \mathrm{~mm}$ well) and images were taken at a $Z$-plane of middle of zeolitic crystal. The software NIS-Elements Ar and N-SIM Analysis were used to analyze the collected images and computationally reconstruct the super-resolution image.

\section{Data availability}

The data that support the findings of this study are available from the corresponding author M.Y. upon reasonable request.

\section{Code availability}

The code used in this paper is available from the corresponding authors M.Y. upon reasonable request.

Received: 27 July 2020; Accepted: 16 November 2020; Published online: 04 January 2021

\section{References}

1. Tian, P., Wei, Y., Ye, M. \& Liu, Z. Methanol to olefins (MTO): from fundamentals to commercialization. ACS Catal. 5, 1922-1938 (2015).

2. Yarulina, I., Chowdhury, A. D., Meirer, F., Weckhuysen, B. M. \& Gascon, J. Recent trends and fundamental insights in the methanol-to-hydrocarbons process. Nat. Catal. 1, 398-411 (2018).

3. Olsbye, U. et al. Conversion of methanol to hydrocarbons: how zeolite cavity and pore size controls product selectivity. Angew. Chem. Int. Ed. 51, 5810-5831 (2012)

4. Ye, M., Li, H., Zhao, Y., Zhang, T. \& Liu, Z. MTO processes development: the key of mesoscale studies. Adv. Chem. Eng. 47, 279-335 (2015).

5. Martens, J. A. et al. The cemical route to a carbon dioxide neutral world. ChemSusChem 10, 1039-1055 (2017).

6. Yarulina, I. et al. Structure-performance descriptors and the role of lewis acidity in the methanol-to-propylene process. Nat. Chem. 10, 804-812 (2018).

7. Kang, J. H., Alshafei, F. H., Zones, S. I. \& Davis, M. E. Cage-defining ring: a molecular sieve structural indicator for light olefin product distribution from the methanol-to-olefins reaction. ACS Catal. 9, 6012-6019 (2019).

8. Ferri, P. et al. Chemical and structural parameter connecting cavity architecture, confined hydrocarbon pool species, and MTO product selectivity in small-pore cage-based zeolites. ACS Catal. 9, 11542-11551 (2019).

9. Li, J. et al. Cavity controls the selectivity: insights of confinement effects on MTO reaction. ACS Catal. 5, 661-665 (2015)

10. Borodina, E. et al. Influence of the reaction temperature on the nature of the active and deactivating species during methanol-to-olefins conversion over $\mathrm{H}$ SAPO-34. ACS Catal. 7, 5268-5281 (2017).

11. Li, C. et al. Synthesis of reaction-adapted zeolites as methanol-to-olefins catalysts with mimics of reaction intermediates as organic structure-directing agents. Nat. Catal. 1, 547-554 (2018).

12. Hemelsoet, K. et al. Identification of intermediates in zeolite-catalyzed reactions by in situ UV/Vis microspectroscopy and a complementary set of molecular simulations. Chem. Eur. J. 19, 16595-16606 (2013).

13. Wulfers, M. J. \& Jentoft, F. C. The role of cyclopentadienium ions in methanol-to-hydrocarbons chemistry. ACS Catal. 4, 3521-3532 (2014).

14. Bhan, A., Allian, A. D., Sunley, G. J., Law, D. J. \& Iglesia, E. Specificity of sites within eight-membered ring zeolite channels for carbonylation of methyls to acetyls. J. Am. Chem. Soc. 129, 4919-4924 (2007).

15. Zhou, J. et al. Presituated "coke"-determined mechanistic route for ethene formation in the methanol-to-olefins process on SAPO-34 catalyst. J. Catal. 377, 153-162 (2019).

16. Gao, M., Li, H., Ye, M. \& Liu, Z. An approach for predicting intracrystalline diffusivities and adsorption entropies in nanoporous crystalline materials. AIChE J. 66, e16991 (2020).

17. Wang, S. et al. Evolution of aromatic species in supercages and its effect on the conversion of methanol to olefins over H-MCM-22 zeolite: a density functional theory study. J. Phys. Chem. C 120, 27964-27979 (2016)

18. Luo, M. et al. Water inhibits the conversion and coking of olefins on SAPO34. Appl. Catal. A 570, 209-217 (2019).

19. Wang, N. et al. Molecular elucidating of an unusual growth mechanism for polycyclic aromatic hydrocarbons in confined space. Nat. Commun. 11, 1079 (2020).

20. Song, Y. et al. Dry reforming of methane by stable Ni-Mo nanocatalysts on single-crystalline MgO. Science 367, 777-781 (2020).

21. Zhou, J. et al. Partial regeneration of spent SAPO-34 catalyst in methanol to olefins process via steam gasification. Ind. Eng. Chem. Res. 57, 17338-17347 (2018).

22. Corma, A., Sauvanaud, L., Doskocil, E. \& Yaluris, G. Coke steam reforming in FCC regenerator: a new mastery over high coking feeds. J. Catal. 279, 183-195 (2011).

23. Yang, M., Fan, D., Wei, Y., Tian, P. \& Liu, Z. Recent progress in methanol-toolefins (MTO) catalysts. Adv. Mater. 31, 1902181 (2019).

24. Martínez-Espín, J. S. et al. Hydrogen transfer versus methylation: on the genesis of aromatics formation in the methanol-to-hydrocarbons reaction over H-ZSM-5. ACS Catal. 7, 5773-5780 (2017).

25. Khare, R. \& Bhan, A. Mechanistic studies of methanol-to-hydrocarbons conversion on diffusion-free MFI samples. J. Catal. 329, 218-228 (2015).

26. Liu, Y. et al. Critical role of formaldehyde during methanol conversion to hydrocarbons. Nat. Commun. 10, 1462 (2019).

27. Gao, M. et al. Direct quantification of surface barriers for mass transfer in nanoporous crystalline materials. Commun. Chem. 2, 43 (2019).

28. Song, W., Fu, H. \& Haw, J. F. Selective synthesis of methylnaphthalenes in HSAPO-34 cages and their function as reaction centers in methanol-to-olefin catalysis. J. Phys. Chem. B 105, 12839-12843 (2001).

29. Hemelsoet, K. et al. The effect of confined space on the growth of naphthalenic species in a chabazite-type catalyst: a molecular modeling study. ChemCatChem 1, 373-378 (2009). 
30. Hemelsoet, K., Nollet, A., Van Speybroeck, V. \& Waroquier, M. Theoretical simulations elucidate the role of naphthalenic species during methanol conversion within H-SAPO-34. Chem. Eur. J. 17, 9083-9093 (2011).

31. De Wispelaere, K., Hemelsoet, K., Waroquier, M. \& Van Speybroeck, V. Complete low-barrier side-chain route for olefin formation during methanol conversion in H-SAPO-34. J. Catal. 305, 76-80 (2013).

32. Wispelaere, K. D. et al. Insight into the effect of water on the methanol-toolefins conversion in H-SAPO-34 from molecular simulations and in situ microspectroscopy. ACS Catal. 6, 1991-2002 (2016).

33. Müller, S. et al. Coke formation and deactivation pathways on H-ZSM-5 in the conversion of methanol to olefins. J. Catal. 325, 48-59 (2015).

34. Arora, S. S., Nieskens, D. L., Malek, A. \& Bhan, A. Lifetime improvement in methanol-to-olefins catalysis over chabazite materials by high-pressure $\mathrm{H}_{2}$ cofeeds. Nat. Catal. 1, 666-672 (2018).

35. Zhao, X. et al. Achieving a superlong lifetime in the zeolite-catalyzed mto reaction under high pressure: synergistic effect of hydrogen and water. ACS Catal. 9, 3017-3025 (2019).

36. Wang, Q. et al. Decomposition of pyrene by steam reforming: the effects of operational conditions and kinetics. Fuel Process. Technol. 182, 88-94 (2018).

37. Magnoux, P., Guisnet, M., Mignard, S. \& Cartraud, P. Coking, aging, and regeneration of zeolites: VIII. Nature of coke formed on hydrogen offretite during n-heptane cracking: mode of formation. J. Catal. 117, 495-502 (1989).

38. An, H. et al. Investigating the coke formation mechanism of H-ZSM-5 during methanol dehydration using operando UV-Raman spectroscopy. ACS Catal. 8, 9207-9215 (2018).

39. Signorile, M. et al. Operando UV-Raman study of the methanol to olefins reaction over SAPO-34: spatiotemporal evolution monitored by different reactor approaches. Catal. Today 336, 203-209 (2019).

40. Signorile, M. et al. Topology-dependent hydrocarbon transformations in the methanol-to-hydrocarbons reaction studied by operando UV-Raman spectroscopy. Phys. Chem. Chem. Phys. 20, 26580-26590 (2018).

41. Grahn, M. et al. Small ZSM-5 crystals with low defect density as an effective catalyst for conversion of methanol to hydrocarbons. Catal. Today 345 , 136-146 (2020).

42. Lezcano-Gonzalez, I. et al. Insight into the effects of confined hydrocarbon species on the lifetime of methanol conversion catalysts. Nat. Mater. 19, 1081-1087 (2020).

43. Borodina, E. et al. Influence of the reaction temperature on the nature of the active and deactivating species during methanol to olefins conversion over $\mathrm{H}$ SSZ-13. ACS Catal. 5, 992-1003 (2015).

44. Cnudde, P. et al. Light olefin diffusion during the MTO process on H-SAPO34: a Complex Interplay of molecular factors. J. Am. Chem. Soc. 142 6007-6017 (2020).

45. Ferri, P. et al. Impact of zeolite framework composition and flexibility on methanol-to-olefins selectivity: confinement or diffusion? Angew. Chem. Int. Ed. 59, 19708-19715 (2020).

46. Mores, D., Kornatowski, J., Olsbye, U. \& Weckhuysen, B. M. Coke formation during the methanol-to-olefin conversion: in situ microspectroscopy on individual H-ZSM-5 crystals with different Brønsted acidity. Chem. Eur. J. 17, 2874-2884 (2011).

47. Qian, Q. et al. Single-particle spectroscopy on large SAPO-34 crystals at work: methanol-to-olefin versus ethanol-to-olefin processes. Chem. Eur. J. 19, 11204-11215 (2013).

48. Whiting, G. T., Nikolopoulos, N., Nikolopoulos, I., Chowdhury, A. D. \& Weckhuysen, B. M. Visualizing pore architecture and molecular transport boundaries in catalyst bodies with fluorescent nanoprobes. Nat. Chem. 11, 23-31 (2019).

49. Van Speybroeck, V. et al. Mechanistic studies on chabazite-type methanol-toolefin catalysts: insights from time-resolved UV/Vis microspectroscopy combined with theoretical simulations. ChemCatChem 5, 173-184 (2012).

50. Hemelsoet, K. et al. Identification of intermediates in zeolite-catalyzed reactions by in situ UV/Vis microspectroscopy and a complementary set of molecular simulations. Chem. Eur. J. 19, 16595-16606 (2013).

51. Gao, M. et al. Imaging spatiotemporal evolution of molecules and active sites in zeolite catalyst during methanol-to-olefins reaction. Nat. Commun. 11, 3641 (2020).

52. Frisch, M. et al. Gaussian 09, Revision B.01 (Gaussian Inc., Wallingford, CT, 2010).

53. Wragg, D. S. et al. SAPO-34 methanol-to-olefin catalysts under working conditions: a combined in situ powder X-ray diffraction, mass spectrometry and Raman study. J. Catal. 268, 290-296 (2009).

54. Zhang, W. et al. Methanol to olefins reaction route based on methylcyclopentadienes as critical intermediates. ACS Catal. 9, 7373-7379 (2019).
55. Chai, J.-D. \& Head-Gordon, M. Long-range corrected hybrid density functionals with damped atom-atom dispersion corrections. Phys. Chem. Chem. Phys. 10, 6615-6620 (2008).

56. Johnson, E. R. et al. Revealing noncovalent interactions. J. Am. Chem. Soc. 132, 6498-6506 (2010).

57. Lu, T. \& Chen, F. Multiwfn: a multifunctional wavefunction analyzer. J. Comput. Chem. 33, 580-592 (2012).

58. Ghysels, A. et al. Shape-selective diffusion of olefins in 8-ring solid acid microporous zeolites. J. Phys. Chem. C 119, 23721-23734 (2015).

59. Wu, P. et al. Synthesis of nanosized SAPO-34 with the assistance of bifunctional amine and seeds. Chem. Commun. 54, 11160-11163 (2018).

60. Gao, S. et al. Insight into the deactivation mode of methanol-to-olefins conversion over SAPO-34: coke, diffusion, and acidic site accessibility. J. Catal. 367, 306-314 (2018).

61. Wong, Y. C., Ysselstein, D. \& Krainc, D. Mitochondria-lysosome contacts regulate mitochondrial fission via RAB7 GTP hydrolysis. Nature 554, 382 (2018).

62. Qi, Q. et al. A H-bond strategy to develop acid-resistant photoswitchable rhodamine spirolactams for super-resolution single-molecule localization microscopy. Chem. Sci. 10, 4914-4922 (2019).

\section{Acknowledgements}

The authors thank the financial support from the National Natural Science Foundation of China (Grant No. 91834302) and Innovation program of science and research from Dalian Institute of Chemical Physics (DICP I201938). We also thank the kind help from Prof. Peng Tian and Dr. Pengfei Wu for the synthesis of SAPO-34 zeolite, Mr. ShanFan Lin for the ${ }^{12} \mathrm{C}-/{ }^{13} \mathrm{C}$-methanol switch experiments, Prof. Fengtao Fan and Mr. Fei Zhang for the UV-Raman spectra measurements and Dr. Lihong Wan for the MALDI FT-ICR MS measurements.

\section{Author contributions}

M.Y. and Z.L. proposed and supervised the project. J.Zho and M.G. designed and carried out the experiments. J.Zha carried out the pilot experiments. M.G. carried out the simulation work. M.G., L.W., and X.Z. performed the SIM characterization analysis. H.L. and T.Z. helped analyze the data. All authors discussed the results and assisted during manuscript preparation.

\section{Competing interests}

The authors declare no competing interests.

\section{Additional information}

Supplementary information is available for this paper at https://doi.org/10.1038/s41467 020-20193-1.

Correspondence and requests for materials should be addressed to M.Y. or Z.L.

Peer review information Nature Communications thanks Javier Ruiz-Martinez and the other, anonymous, reviewer(s) for their contribution to the peer review of this work.

Reprints and permission information is available at http://www.nature.com/reprints

Publisher's note Springer Nature remains neutral with regard to jurisdictional claims in published maps and institutional affiliations.

Open Access This article is licensed under a Creative Commons Attribution 4.0 International License, which permits use, sharing, adaptation, distribution and reproduction in any medium or format, as long as you give appropriate credit to the original author(s) and the source, provide a link to the Creative Commons license, and indicate if changes were made. The images or other third party material in this article are included in the article's Creative Commons license, unless indicated otherwise in a credit line to the material. If material is not included in the article's Creative Commons license and your intended use is not permitted by statutory regulation or exceeds the permitted use, you will need to obtain permission directly from the copyright holder. To view a copy of this license, visit http://creativecommons.org/ licenses/by/4.0/.

(C) The Author(s) 2021 